\title{
Can experimentally induced positive affect attenuate generalization of fear of movement-related pain?
}

Citation for published version (APA):

Geschwind, N., Meulders, M., Peters, M. L., Vlaeyen, J. W. S., \& Meulders, A. (2015). Can experimentally induced positive affect attenuate generalization of fear of movement-related pain? The Journal of Pain, 16(3), 258-269. https://doi.org/10.1016/j.jpain.2014.12.003

Document status and date:

Published: 01/03/2015

DOI:

10.1016/j.jpain.2014.12.003

Document Version:

Publisher's PDF, also known as Version of record

Document license:

Taverne

Please check the document version of this publication:

- A submitted manuscript is the version of the article upon submission and before peer-review. There can be important differences between the submitted version and the official published version of record.

People interested in the research are advised to contact the author for the final version of the publication, or visit the DOI to the publisher's website.

- The final author version and the galley proof are versions of the publication after peer review.

- The final published version features the final layout of the paper including the volume, issue and page numbers.

Link to publication

\footnotetext{
General rights rights.

- You may freely distribute the URL identifying the publication in the public portal. please follow below link for the End User Agreement:

www.umlib.nl/taverne-license

Take down policy

If you believe that this document breaches copyright please contact us at:

repository@maastrichtuniversity.nl

providing details and we will investigate your claim.
}

Copyright and moral rights for the publications made accessible in the public portal are retained by the authors and/or other copyright owners and it is a condition of accessing publications that users recognise and abide by the legal requirements associated with these

- Users may download and print one copy of any publication from the public portal for the purpose of private study or research.

- You may not further distribute the material or use it for any profit-making activity or commercial gain

If the publication is distributed under the terms of Article $25 \mathrm{fa}$ of the Dutch Copyright Act, indicated by the "Taverne" license above, 


\title{
Can Experimentally Induced Positive Affect Attenuate Generalization of Fear of Movement-Related Pain?
}

\author{
Nicole Geschwind, ${ }^{*}$ Michel Meulders, ${ }^{\dagger, \star}$ Madelon L. Peters, ${ }^{*}$ Johan W. S. Vlaeyen, ${ }^{*}, \S$, \\ and Ann Meulders ${ }^{\S,}$ \\ *Department of Clinical Psychological Science, Maastricht University, Maastricht, The Netherlands. \\ ${ }^{\dagger}$ Department of Informatics, Simulation and Modeling, KU Leuven, Belgium. \\ ${ }^{\ddagger}$ Research Group on Quantitative Psychology and Individual Differences, KU Leuven, Belgium. \\ ${ }^{\S}$ Research Group on Health Psychology, KU Leuven, Belgium. \\ ${ }^{\top}$ Center for Excellence on Generalization Research in Health and Psychopathology, KU Leuven, Belgium.
}

\begin{abstract}
Recent experimental data show that associative learning processes are involved not only in the acquisition but also in the spreading of pain-related fear. Clinical studies suggest involvement of positive affect in resilience against chronic pain. Surprisingly, the role of positive affect in associative learning in general, and in fear generalization in particular, has received scant attention. In a voluntary movement paradigm, in which one arm movement (reinforced conditioned stimulus [CS+]) was followed by a painful stimulus and another was not (unreinforced conditioned stimulus [CS-]), we tested generalization of fear inhibition in response to 5 novel but related generalization movements (GSs; within-subjects) after either a positive affect induction or a control exercise (Group $=$ between-subjects) in healthy participants $(N=50)$. The GSs' similarity with the original CS + movement and CS- movement varied. Fear learning was assessed via verbal ratings. Results indicated that there was an interaction between the increase in positive affect and the linear generalization gradient. Stronger increases in positive affect were associated with steeper generalization curves because of relatively lower pain-unconditioned stimulus expectancy and less fear of stimuli more similar to the CS-. There was no Group by Stimulus interaction. Results thus suggest that positive affect may enhance safety learning through promoting generalization from known safe movements to novel yet related movements. Improved safety learning may be a central mechanism underlying the association between positive affect and increased resilience against chronic pain.

Perspective: We investigated the extent to which positive affect influences the generalization (ie, spreading) of pain-related fear inhibition in response to situations similar to the original, paineliciting situation. Results suggest that increasing positive affect in the acute pain stage may limit the spreading of pain-related fear, thereby potentially inhibiting transition to chronic pain conditions.
\end{abstract}

(c) 2015 by the American Pain Society

Key words: Fear of movement-related pain, positive affect, best positive self, fear generalization, voluntary movement paradigm, safety signal.

\footnotetext{
Received June 27, 2014; Revised November 21, 2014; Accepted December 10, 2014.

The authors thank Manou van der Walle for her assistance in the data collection and Jeroen Clarysse for his technical support.

A.M. is a postdoctoral researcher of the Research Foundation Flanders (FWO-Vlaanderen), Belgium (12E33714 N). The participation of N.G. was made possible by the Center for Excellence on Generalization research, KU Leuven, Belgium (GRIP*TT; KU Leuven grant PF/10/005). The study was also supported by the Odysseus Grant "The Psychology of Pain and Disability Research Program" funded by the Research Foundation Flanders (FWO-Vlaanderen), Belgium to J.W.S.V. (G090208N) and by an EFIC-Grünenthal Research Grant (E-G-G ID: 169518451) to A.M. The authors report no conflict of interest.

Supplementary data accompanying this article are available online at www.jpain.org and www.sciencedirect.com.

Address reprint requests to Ann Meulders, PhD, Department of Psychology, University of Leuven, Tiensestraat 102, Box 3726, 3000 Leuven, Belgium. E-mail: ann.meulders@ppw.kuleuven.be

$1526-5900 / \$ 36.00$

(c) 2015 by the American Pain Society

http://dx.doi.org/10.1016/j.jpain.2014.12.003
}

- ear-avoidance models have identified pain-related - fear as a key psychological factor involved in the transition from acute to chronic pain disability. 1,10,11,27,28 However, in chronic pain patients, fear is often not restricted to movements associated with pain during the initial pain episode, but rather generalizes (ie, spreads) to similar novel stimuli. ${ }^{12,18,20}$ Recent experimental research suggests that overgeneralization of fear of other stimuli may be particularly immobilizing, more so than intense fear of the initial trigger. ${ }^{13,15}$ To illustrate, developing fear of all furry animals after being bitten by a poodle is more incapacitating for daily-life functioning than is intense fear of that particular poodle.

In a typical fear conditioning experiment, a neutral stimulus is paired with an aversive stimulus. A recent 
study investigated pain-related fear generalization in a paradigm in which one arm movement (the reinforced conditioned stimulus; $\mathrm{CS}+$ ) was followed by pain (the unconditioned stimulus; US), and another movement was not (the unreinforced conditioned stimulus; (S-). ${ }^{18}$ Results indicated that pain-related fear generalized selectively to novel movements that were more similar to the original CS+ than to the CS-, thus for the first time showing a generalization gradient for fear of movement-related pain (ie, a linear increase in fear from CS- to CS + via the intermediate stimuli).

Fear-avoidance models acknowledge negative affect (NA; the experience of unpleasant emotions such as sadness or anxiety) as an important factor in the development of pain-related fear. ${ }^{27}$ Remarkably, both fearavoidance models and fear conditioning research have paid only scant attention to the role of positive affect (PA; the experience of pleasant emotions such as joy or gratitude). ${ }^{25}$ This lack of research is surprising because PA is known to be involved in more adaptive coping and in undoing the psychological and cardiovascular consequences of stress., ${ }^{4,5}$ In addition, PA and NA arguably represent different subsystems, rather than opposite endpoints of a single affective continuum. ${ }^{21}$ Consequently, the effects of PA cannot be assumed to be exactly opposite to the effects of NA. Accordingly, Zautra and colleagues have found that fibromyalgia patients display a lack of PA but not a surplus of NA during pain and stress, compared to healthy controls. ${ }^{29}$ A study on chronic pain patients found that PA was inversely related to pain ratings in subsequent weeks. ${ }^{30}$ Meulders and colleagues ${ }^{16}$ found that trait PA was associated with different safety learning patterns under extinction (ie, when the pain-US was omitted). Participants with relatively low trait PA were less sure that the previously safe CS- was still safe, compared to participants with relatively high trait PA, indicating failure of fear inhibition. $^{17}$

To our knowledge, no studies have investigated the association between PA and generalization of painrelated fear of other stimuli. This relationship is of particular interest given the possibility that unrestrained spreading of fear is also due to failure to inhibit fear responses. A better understanding of how PA influences generalization is important to optimize prevention and treatment strategies for patients with disabling chronic pain.

Therefore, we aimed to investigate the role of experimentally induced PA on the generalization of painrelated fear. In a voluntary movement joystick paradigm, one arm movement (CS+) was selectively paired with pain, whereas another was not (CS-). After acquisition but before test of generalization (presentation of 5 novel movements; generalization stimuli [GSs]), participants completed either a PA induction or a control exercise. Following the above-mentioned evidence for improved safety learning, we hypothesized that stronger increases in PA would more strongly inhibit generalization of expectancy and fear of pain to stimuli that are more similar to the original CS-, thereby resulting in steeper generalization gradients.

\section{Methods}

\section{Participants}

Fifty healthy females (mean [M] age $=20.32$ years, standard deviation $[S D]=1.97$, range $=18-26$ ) freely chose their more valued compensation (course credit or financial compensation) for their participation: 1) 37 psychology students of the University of Leuven received course credits, and 2) 13 volunteers were paid $€ 15$. Participants confirmed not being pregnant and not having respiratory or cardiovascular diseases, neurologic diseases (eg, epilepsy), or any other minor or major illness, including chronic pain. Participants were randomly allocated to either the PA induction group $(n=25)$ or the control group $(n=25)$, stratified by hand preference (left/right). Seven of 50 participants were left-handed. Additional exclusion criteria were uncorrected hearing problems and pain at the dominant hand or wrist. The experimental protocol was approved by the Ethical Committee of the Faculty of Psychology and Educational Sciences of the University of Leuven (registration number: S-54568) and the Medical Ethical Committee of the University Hospital of the University of Leuven (registration number: ML8513). All participants provided informed consent, which explicitly stated that they were allowed to decline participation at any time during the experiment.

\section{Stimulus Material}

The pain-US was a nociceptive electrocutaneous stimulus (square wave form, wavelength $100 \lambda$ ). Electrical stimulation was administered by a commercial constant current stimulator (DS5; Digitimer, Welwyn Garden City, England) through surface SensorMedics (Homestead, $\mathrm{FL}$ ) electrodes ( $8 \mathrm{~mm}$ ) filled with K-Y gel (Johnson \& Johnson, New Brunswick, NJ). The electrodes were attached to the wrist of the dominant hand. The location of the stimulation site remained the same throughout the experiment. During the calibration procedure, participants received a series of electrocutaneous stimuli of increasing intensity and were asked to indicate how painful each stimulus was on a scale ranging from 1, "I feel something but this is not painful, it is merely a sensation"; 2, "This sensation starts to be painful, but it is still a very moderate pain"; up to 10 "This is the worst tolerable pain I can imagine." Participants were told that a subjective stimulus intensity of 8 , which refers to a stimulus that is "significantly painful and demanding some effort to tolerate," was targeted. Intermediate digits were displayed without labels. Mean subjective stimulus intensity was $7.72, \mathrm{SD}=.72$, range $=5-9$.

Two proprioceptive stimuli (ie, moving a Paccus Hawk [Paccus Interfaces BV, Almere, The Netherlands] joystick to the left or to the right with an upward angle of $30^{\circ}$ ) served as conditioned stimuli (CSs). During acquisition, one movement direction $(\mathrm{CS}+)$ was followed by the pain-US in $75 \%$ of the trials (ie, $75 \%$ reinforcement), whereas the other movement direction was never followed by the pain-US (CS-); which movement direction served as CS+ or CS- was counterbalanced across 
participants. The GSs were 3 intermediate movement directions (left and right with upward angles of $60^{\circ}$ to the horizontal plane, and a vertical movement upward in $90^{\circ}$ ), as well as 2 more extreme movements (ie, to the left and to the right in the horizontal plane with angles of 0 and $180^{\circ}$; see Fig 1). The experiment was run on a Windows XP computer (Dell Optiplex 755; Dell Inc, Round Rock, TX) with 2 GB random-access memory and an Intel Core2 Duo processor (Intel Corp, Santa Clara, CA) at $2.33 \mathrm{GHz}$ and an ATI Radeon 2400 graphics card (Advanced Micro Devices, Inc, Sunnyvale, CA) with $256 \mathrm{MB}$ of video random-access memory, using Affect 4.0. ${ }^{24}$

\section{Experimental Setting}

Participants were seated in an armchair (.6 m screen distance to a Dell E176FP 17" Flat Panel Monitor) in a sound-attenuated and dimmed experimental room, adjacent to the experimenter's room. Verbal communication was possible through an intercom system; the experimenter observed the participants by means of a closed-circuit television installation.

\section{Procedure}

The experiment was conducted during a 90-minute individual session and consisted of 1) a practice phase, 2) an acquisition phase, 3) a transfer of acquisition phase, 4) an affect induction phase, and 5) a test of generalization. The experimental procedure also included the placement of 3 facial electrodes related to the measurement of fear-potentiated eyeblink startle. For the sake of readability and brevity, we decided to omit the description of startle measure and all related aspects because of the following difficulties: In order to mimic real chronic pain conditions more closely (patients typically experience increasing pain during movements), we had decided to present the pain-US concurrently with the $\mathrm{CS}+$ movement. However, because of design difficulties, the onset of the pain-US ( $M=187.00$ milliseconds, $\mathrm{SD}=98.06$ ) appears to have occurred significantly earlier than onset of startle probe $(M=313.59$ milliseconds, $\mathrm{SD}=170.96), \mathrm{F}(1,48)=76.54, P<.001$. Consequently, the analysis revealed no reliable acquisition effect in the startle measures, $\mathrm{F}(3,141)=1.40, P=.24$, rendering the startle measure unreliable as an index of anticipatory fear. For more information on the startle-related procedure used this study, please see Meulders et al. ${ }^{19}$

We used an adapted version of the voluntary joystick movement task, ${ }^{19}$ in which participants moved the joystick to the left and to the right with a $30^{\circ}$ angle to the horizontal plane during the practice and (transfer of) acquisition phases. One movement direction (CS + ) was accompanied by the pain-US in $75 \%$ of the trials, and the other movement (CS-) was never followed by the pain-US. The direction of joystick movement (left or right with a $30^{\circ}$ angle) that served as CS+ and CS- was counterbalanced across participants. During practice and acquisition training, participants voluntarily initiated the order of their movements, so they freely chose in which direction they were going to move first, but they had to complete both movements during each block. During the transfer of acquisition phase, however, they could no longer choose the order of the movements themselves, but the movement direction was signaled. In the affect induction phase, participants completed either an exercise designed to induce PA (Best Possible Self [BPS $]^{2,6,22}$ ) or a control exercise (Typical $\operatorname{Day}^{2,6,22}$ ). The test of generalization used the same signaling procedure as during the transfer phase to test

\section{Practice \& Acquisition}

$4 \times \mathrm{CS}+$ only $16 \times \mathrm{CS}+(75 \%$ pain-US)

$4 \times$ CS- $16 \times$ CS-

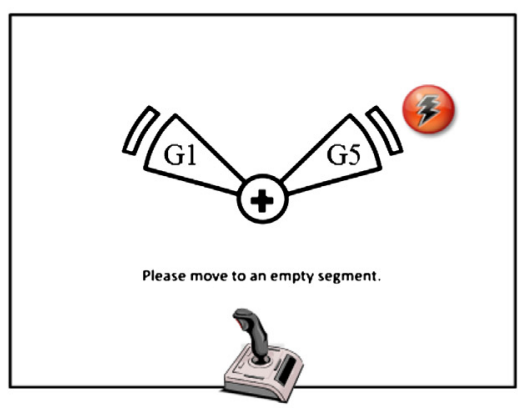

Transfer of Acquisition

$8 \times \mathrm{CS}+(75 \%$ pain-US $)$

$8 \times$ CS-

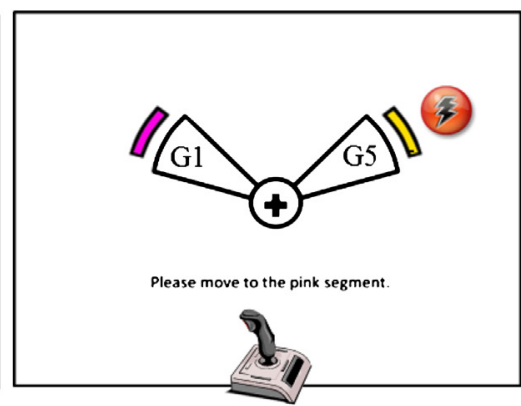

\section{Generalization}

$3 \times \mathrm{CS}+(33 \%$ pain-US)

$3 \times \mathrm{CS}-$

$3 \times \mathrm{G} 0 / \mathrm{G} 2 / \mathrm{G} 3 / \mathrm{G} 4 / \mathrm{G} 6$

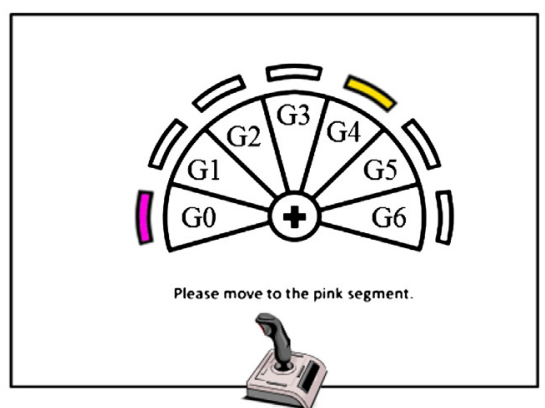

Figure 1. Schematic design overview of the voluntary joystick movement task per phase: practice and acquisition (left panel), transfer of acquisition (middle panel), and test of generalization (right panel). The 2 equally spaced movement quadrants that served as CSs (G1 and G5) were delineated by black borders (left panel). Participants had to move the joystick until they reached the rectangular target that was positioned at the end of the movement quadrant; the corresponding blank target turned yellow when a movement was successfully performed. During the practice phase, no pain-USs were delivered. During the acquisition phase, participants carried out 2 CS movements (G1 and G5). After the "+", the starting signal disappeared in the middle of the screen, and participants had to move freely in the direction that they chose. One of these movements was followed by a pain-US on $75 \%$ of the trials (CS + , ie, right) indicated by a lightning bolt, whereas the other movement (CS-,ie, left) was never followed by the pain-US. Which movement direction served as the CS + or CS - was counterbalanced across participants. Next, during the transfer-of-acquisition (middle panel) phase, participants could no longer choose the movement direction; the direction was "signaled" by coloring the corresponding target pink. Finally, during the generalization phase (right panel), participants had to perform all CS and GS movements (G0-G6) using the same signaling procedure; only the first CS+ movement was reinforced during this phase, and GSs were never reinforced. 
Geschwind et al

conditioned responding to novel intermediate as well as more extreme movements (GSs). The different phases and exercises are described in more detail below.

\section{Preparation Phase}

Upon arrival in the laboratory, participants were informed (orally and in writing) that painful electrocutaneous stimuli (pain-USs) would be administered during the experiment. After providing informed consent, participants went to the experimental room. Next, the intensity level of the pain-US was selected following the calibration procedure (see Stimulus Material).

\section{Practice Phase}

Fig 1 provides an illustrative overview of the design and the voluntary joystick movement task. Before starting the practice phase, participants received detailed instructions about the experimental task. In each of the 4 blocks, they were requested to move the joystick toward a blank target at the end of 2 equally spaced movement quadrants when prompted by the disappearance of a starting signal "+" (fixation cross presented in the middle of the computer screen for 1,000 milliseconds before each movement). Within each block, participants had to perform both the left and the right movement, but they could choose the order of the movements themselves. A successful movement always resulted in coloring the corresponding target yellow. After both movement directions were performed, the colors were reset to blank and the next block started. In total, 4 blocks with a left and a right movement each were run. During the practice phase, no pain-USs were presented and online verbal feedback about the task performance was provided by the experimenter.

\section{Acquisition Phase}

This phase was largely identical to the practice phase with the exception that 1) pain-USs were presented and 2) 16 blocks of 2 trials ( 1 to the left and 1 to the right) were run instead of 4 blocks. Although a CS movement was of variable length depending on the participant's movement speed, a trial always included an intertrial interval consisting of a pre-CS interval of 3.5 seconds and a post-CS interval of 5.5 seconds. The pain-US was presented on $75 \%$ of the CS+ trials (75\% reinforcement). The pain-US started early during the CS+ movement (eg, to the right) and ended when the target was reached and colored yellow; during CS- movements, no pain-USs were delivered (eg, to the left). After every fourth conditioning block, participants rated pain-US expectancy and fear of movement-related pain associated with the CSs. Note that participants were never informed about the contingencies between the joystick movement directions (CSS) and the occurrence of the pain-US.

\section{Transfer-of-Acquisition Phase}

In the transfer-of-acquisition phase, 8 blocks of 2 trials were run. Trials were identical to the acquisition phase except that CS movements were no longer voluntarily initiated, but signaled. On a certain trial, 1 of the targets at the end of the movement quadrant was colored pink, and participants were instructed to move toward the pink-colored target. The pink target again colored yellow when participants had performed the movement correctly. Every other block, before actually performing the signaled movement, participants rated their painUS expectancy and fear of movement-related pain for both movements. After completing the ratings, participants waited for the "+" starting signal to start moving into the signaled movement direction.

\section{Affect Induction Phase}

In this phase, participants were randomized to complete either the BPS or the Typical Day exercise, both including writing and visualization. Possibly because of activating achievement cognitions regarding important life goals, the BPS has been previously shown to selectively increase optimism, PA, and positive future expectancies, but not to decrease NA in pain-related experiments. ${ }^{2,6,22}$ In the current study, we used the BPS to experimentally increase levels of PA. Specifically, participants in the PA group were asked to first think about (1 minute) and subsequently write about a future in which everything goes well and in which they realize their dreams (15 minutes), and then to visualize this scenario for 5 minutes. ${ }^{22}$ In the control group, equivalent instructions to think, write about, and visualize a typical day were used. ${ }^{2,6,22}$

\section{Test of Generalization}

The test of generalization started immediately after the affect induction phase and lasted about 10 to 15 minutes. The procedure during the test of generalization was largely the same as during the transfer-ofacquisition phase. However, besides the original CS movements, participants now performed 5 novel generalization movements (GSs) with movement angles either intermediate to (G2-G3-G4) or more extreme than (G0 and G6) the original CS + (G5) and CS- (G1) movement directions (see Stimulus Material and Fig 1) in randomized order. Stimuli were presented in 3 blocks of 7 trials. Again the pink-colored target signaled which movement had to be performed. During the first block, participants rated their pain-US expectancy and fear of movementrelated pain associated with moving in the signaled direction and then waited for the starting signal "+," before actually performing the signaled movement. The CS + was reinforced during the first block of the test of generalization and was unreinforced during the second and third blocks to allow for measurement of the (in retrospect unreliable and therefore not included) fear-potentiated eyeblink startle (see above).

\section{Outcome Measures}

\section{Pain-US Expectancy}

Pain-US expectancy was measured with the question "To what extent do you expect an electrical stimulus when performing the left/right movement?" (or "the signaled movement," depending on the phase of the 
experiment). Participants indicated their answers on a vertical computerized visual analog scale (range $=0$ 100) with anchors "not at all," "moderate," and "very much." During the acquisition phase, pain-US expectancy was rated after every fourth block. Participants rated their pain-US expectancy before each movement during the test of generalization (each block) and during the transfer-of-acquisition phase (every other block).

\section{Self-Reported Fear of Movement-Related Pain}

To assess self-reported fear of movement-related pain, participants repeatedly answered the visual analog scale item "How afraid are you to perform the left/right movement?" (or the "signaled" movement, depending on the phase of the experiment). Administration and anchors were analogous to the assessment of pain-US expectancy.

\section{Self-Reported PA}

The modified Differential Emotions Scale (mDES) $)^{8,23}$ was used to measure PA. The mDES consists of 16 emotion items measured on a 7-point Likert scale from 1 ("not at all") to 7 ("very intense"). Five items ("joyful, happy, amused"; "warm hearted, gleeful, elated"; "loving, affectionate, friendly"; "moved"; and "satisfied, pleased") were averaged to measure PA. The NA score included 8 items ("sad, downhearted, blue"; "angry, irritated, mad"; "fearful, scared, afraid"; "anxious, tense, nervous"; "disgusted, turned off, repulsed"; "disdainful, scornful, contemptuous"; "guilty, remorseful"; and "ashamed, embarrassed"). The mDES was measured before and after the affect induction phase, and after the test of generalization-thus, approximately 20 minutes later.

\section{Statistical Data Analysis}

In this study, we aimed to study how changes in PA (manipulated by an experimental affect induction) influ- ence generalization of pain-US expectancy and fear of movement-related pain. Some preparatory analyses were necessary in order to test our main research question: First, we conducted 2 separate repeated measures analyses of variance, one on mean PA and the other on mean NA, measured with the mDES with Group (positive/control) as between-subjects factor and Time (pre/ post/follow-up [FU]) as within-subjects factor. Planned contrasts were calculated to check that there was 1) no initial difference between the groups with regard to PA, and 2) a larger increase in PA, and not a decrease in NA, after the BPS exercise in the PA induction group compared to the control group. Second, we tested fear acquisition effects in both dependent variables, that is, we checked whether participants reported more fear and higher US expectancy in response to the $\mathrm{CS}+$ movement than to the CS- movement at the end of the (transfer-of-)acquisition training as compared to the beginning. Therefore, we defined 2 multilevel regression models ( 1 for each dependent variable) to test effects of stimulus type (CS+ or CS-) on the change in ratings of pain-US expectancy and fear of movement-related pain, respectively, during the 4 blocks of acquisition (A1/A2/ A3/A4), and the 2 blocks of the transfer-of-acquisition phase (T1/T2) (see Supplementary Appendix A for the detailed statistical model description). The effects included in each model were estimated simultaneously using the SAS procedure MIXED. ${ }^{7,26}$ Both models are able to predict participants' ratings of pain-US expectancy (see Table 1) and fear of movement-related pain (see Table 2) well as they explain 76 and $72 \%$, respectively, of the observed variance in ratings. We chose to include a random intercept in both models, given that 3.8 and $28.3 \%$, respectively, were due to differences among participants: $\sigma_{\theta}^{2} /\left(\sigma_{\theta}^{2}+\sigma_{\varepsilon}^{2}\right)$. Furthermore, when omitting the random intercept, the variance explained in the ratings of pain-US expectancy and fear of movement-related pain dropped from 76 to $74 \%$ and from 72 to $58 \%$ for

Table 1. Multilevel Regression Predicting Pain-US Expectancy Ratings During the Acquisition and Transfer-of-Acquisition Phase for CS + Versus CS- Movements and for PA Induction Versus Control Group

\begin{tabular}{|c|c|c|c|c|}
\hline CoEfFICIENT & DESCRIPTION & Estimate & $S E$ & P VALUE \\
\hline$\mu^{(-)}$ & $\begin{array}{l}\text { Predicted intercept of the linear trend (ie, at } \mathrm{T}=0 \text { ) for } \mathrm{CS} \text { - movements for subjects with an average } \\
\text { random intercept value (ie, } \theta_{i}=0 \text { ), and averaged over the } 2 \text { groups }\end{array}$ & 13.78 & 3.18 & $<.0001$ \\
\hline$\beta_{\top}^{(-)}$ & Slope of the linear trend for CS- movements, averaged over the 2 groups & 3.84 & 1.01 & .000 \\
\hline$\beta_{E I}^{(-)}$ & $\begin{array}{l}\text { Increase in the intercept of the linear trend (ie, at } \mathrm{T}=0 \text { ) of } \mathrm{CS} \text { - movements for subjects in the PA induction } \\
\text { group compared to the average intercept for both groups }\end{array}$ & -3.16 & 3.18 & .321 \\
\hline$\beta_{\mathrm{T} \times E I}^{(-)}$ & $\begin{array}{l}\text { Increase in the slope of the linear trend of CS- movements for subjects in the PA induction group } \\
\text { compared to the average intercept for both groups }\end{array}$ & 1.67 & 1.01 & .100 \\
\hline$\mu^{(+)}$ & $\begin{array}{l}\text { Predicted intercept of the linear trend (ie, at } \mathrm{T}=0 \text { ) for } \mathrm{CS}+\text { movements for subjects with an average } \\
\text { random intercept value (ie, } \theta_{i}=0 \text { ), averaged over the } 2 \text { groups }\end{array}$ & 55.74 & 3.18 & $<.0001$ \\
\hline$\beta_{\top}^{(+)}$ & Slope of the linear trend for CS+ movements, averaged over the 2 groups & 21.78 & 1.01 & $<.0001$ \\
\hline$\beta_{E I}^{(+)}$ & $\begin{array}{l}\text { Increase in the intercept of the linear trend (ie, at } \mathrm{T}=0 \text { ) of } \mathrm{CS}+\text { movements for subjects in the PA } \\
\text { induction group compared to the average intercept for both groups }\end{array}$ & -.67 & 3.18 & .834 \\
\hline$\beta_{\mathrm{T} \times E I}^{(+)}$ & $\begin{array}{l}\text { Increase in the slope of the linear trend of CS+ movements for subjects in the PA induction group } \\
\text { compared to the average intercept for both groups }\end{array}$ & .07 & 1.01 & .9 \\
\hline$\sigma_{\theta}^{2}$ & Variance of the subject-specific predicted ratings at block $\mathrm{A} 1(\mathrm{ie}, \mathrm{T}=0)$ & 35.7 & 23.0 & .060 \\
\hline$\sigma_{\varepsilon}^{2}$ & Variance of the error term & 898.1 & 54.5 & $<.0001$ \\
\hline$R^{2}$ & Proportion of explained variance & .755 & & \\
\hline
\end{tabular}


Table 2. Multilevel Regression Predicting Fear of Movement-Related Pain Ratings During the Acquisition and Transfer-of-Acquisition Phase for CS+ Versus CS- Movements and for PA Induction Versus Control Group

\begin{tabular}{|c|c|c|c|c|}
\hline COEFFICIENT & DESCRIPTION & ESTIMATE & SE & P VAlUe \\
\hline$\mu^{(-)}$ & $\begin{array}{l}\text { Predicted intercept of the linear trend (ie, at } \mathrm{T}=0 \text { ) for } \mathrm{CS} \text { - movements for subjects with an average } \\
\text { random intercept value (ie, } \theta_{i}=0 \text { ), averaged over the } 2 \text { groups }\end{array}$ & 13.40 & 3.89 & .001 \\
\hline$\beta_{\top}^{(-)}$ & Slope of the linear trend for CS- movements, averaged over the 2 groups & 3.97 & .97 & $<.0001$ \\
\hline$\beta_{E I}^{(-)}$ & $\begin{array}{l}\text { Increase in the intercept of the linear trend (ie, at } \mathrm{T}=0 \text { ) of } \mathrm{CS} \text { - movements for subjects in the PA induction } \\
\text { group compared to the average intercept for both groups }\end{array}$ & -5.07 & 3.89 & .193 \\
\hline$\beta_{\mathrm{T} \times E I}^{(-)}$ & $\begin{array}{l}\text { Increase in the slope of the linear trend of CS- movements for subjects in the PA induction group } \\
\text { compared to the average intercept for both groups }\end{array}$ & 1.22 & .97 & .208 \\
\hline$\mu^{(+)}$ & $\begin{array}{l}\text { Predicted intercept of the linear trend (ie, at } \mathrm{T}=0 \text { ) for } \mathrm{CS}+\text { movements for subjects with an average } \\
\text { random intercept value (ie, } \theta_{i}=0 \text { ), averaged over the } 2 \text { groups }\end{array}$ & 41.61 & 3.89 & $<.0001$ \\
\hline$\beta_{\top}^{(+)}$ & Slope of the linear trend for $\mathrm{CS}+$ movements, averaged over the 2 groups & 18.11 & .97 & $<.0001$ \\
\hline$\beta_{E I}^{(+)}$ & $\begin{array}{l}\text { Increase in the intercept of the linear trend (ie, at } \mathrm{T}=0 \text { ) of } \mathrm{CS}+\text { movements for subjects in the PA } \\
\text { induction group compared to the average intercept for both groups }\end{array}$ & -5.54 & 3.89 & .155 \\
\hline$\beta_{\mathrm{T} \times E I}^{(+)}$ & $\begin{array}{l}\text { Increase in the slope of the linear trend of CS + movements for subjects in the PA induction group } \\
\text { compared to the average intercept for both groups }\end{array}$ & .44 & .97 & .648 \\
\hline$\sigma_{\theta}^{2}$ & Variance of the subject-specific predicted ratings at block $\mathrm{A} 1$ (ie, $\mathrm{T}=0$ ) & 325.7 & 80.6 & $<.0001$ \\
\hline$\sigma_{\varepsilon}^{2}$ & Variance of the error term & 821.3 & 49.8 & $<.0001$ \\
\hline$R^{2}$ & Proportion of explained variance & .716 & & \\
\hline
\end{tabular}

each of the models, respectively. Note that at this point, both groups received identically the same training, and no effects of Group were anticipated.

After these preparatory analyses, we proceeded to test our main hypotheses that during the test of generalization, healthy individuals with relatively high compared to low increases in experimentally induced PA 1) report less fear and 2) show lower US expectancy ratings to the safe CS- movement and to GSs that are more related to the CS-. Originally, we hypothesized the increase in PA to vary with the experimental groups; that is, we expected a higher increase in PA in the PA induction group than in the control group. In order to test this hypothesis, we first defined 2 multilevel regression models with random intercept (1 for each dependent variable) including Group, linear trend variable $T_{j}$ (which equals $0,1,2,3,4,5,6$ for stimuli $j=G_{0}, G_{1(C S-)}, G_{3}, G_{4}$, $\mathrm{G}_{5(\mathrm{CS}+)}, \mathrm{G}_{6}$ ) modeling the generalization gradient, and the interaction between the linear trend and the Group. These analyses did reveal the expected generalization gradient in both the fear of movement-related pain ratings and the pain-US expectancy ratings (respectively: $\beta_{\mathrm{T}}=5.30, P<.0001$, and $\beta_{\mathrm{T}}=6.54$,
$P<.0001)$, but this gradient did not change depending on group status (respectively : $\beta_{\mathrm{T} \times \text { Group }}=1.09, P=.215$, and $\beta_{\mathrm{T} \times \text { Group }}=.66, P=.508$ ). Previous work showed that post hoc "responder" analyses using the actual increase in optimism (across groups, thus including all participants) had more power than analyzing betweengroup differences (M.L.P., 2014, unpublished data). Because the postulated underlying mechanism is the increase in PA, we defined 2 other multilevel regression models ( 1 for each dependent variable) to test the combined effects of change in GS and increase in PA ( $\triangle P A$; a continuous variable reflecting change in PA from pre to post affect induction in all participants [ $N=50])$. The dependent variables were ratings of pain-US expectancy and fear of movement-related pain, respectively, during the test of generalization phase (see Supplementary Appendix B for the detailed statistical model description). The effects included in each model were estimated simultaneously using the SAS procedure MIXED. ${ }^{7,27}$ Both models are able to predict participants' ratings of painUS expectancy (see Table 3) and fear of movementrelated pain (see Table 4) well as they explain 61 and $68 \%$, respectively, of the observed variance in ratings.

\begin{tabular}{|c|c|c|c|c|}
\hline CoEfFICIENT & DESCRIPTION & ESTIMATE & $S E$ & P VALUe \\
\hline$\mu$ & $\begin{array}{l}\text { Predicted rating for stimulus } \mathrm{G}_{0} \text { (ie, } \mathrm{T}=0 \text { ) for subjects with an average } \Delta \mathrm{PA} \text { score (ie, } \Delta \mathrm{PA}=0 \text { ), and an } \\
\text { average random intercept value (ie, } \theta_{i}=0 \text { ) }\end{array}$ & 29.2 & 2.78 & $<.0001$ \\
\hline$\beta_{\mathrm{T}}$ & $\begin{array}{l}\text { Average change in the predicted rating for stimulus } G_{j} v s G_{j-1} \text { for subjects with an average } \triangle P A \text { score } \\
\text { (ie, } \triangle P A=0 \text { ) }\end{array}$ & 6.9 & .50 & $<.0001$ \\
\hline$\beta_{\triangle P A}$ & Average change in the predicted rating for stimulus $G_{0}(i e, T=0$ ) if $\Delta P A$ increases $1 S D$ & -5.9 & 2.81 & .036 \\
\hline$\beta_{\mathrm{T} \times \triangle P A}$ & Predicted change in the slope of the linear trend if the $\triangle \mathrm{PA}$ score increases $1 \mathrm{SD}$ & 1.01 & .50 & .045 \\
\hline$\sigma_{\theta}^{2}$ & Variance of the subject-specific predicted ratings for stimulus $G_{0}(i e, T=0)$ & 225.6 & 56.3 & $<.0001$ \\
\hline$\sigma_{\varepsilon}^{2}$ & Variance of the error term & 346.7 & 28.4 & $<.0001$ \\
\hline $\mathrm{R}^{2}$ & Proportion of explained variance & .605 & & \\
\hline
\end{tabular}


Table 4. Multilevel Regression Predicting Fear of Movement-Related Pain Ratings During the Generalization Phase for Varying Levels of the Increase in PA After Either PA Induction or Control Exercise (ie, Across Groups)

\begin{tabular}{|c|c|c|c|c|}
\hline COEFFICIENT & DESCRIPTION & ESTIMATE & $S E$ & P VALUE \\
\hline$\mu$ & $\begin{array}{l}\text { Predicted rating for stimulus } \mathrm{G}_{0} \text { (ie, } \mathrm{T}=0 \text { ) for subjects with an average } \Delta \mathrm{PA} \text { score (ie, } \Delta \mathrm{PA}=0 \text { ), and an } \\
\text { average random intercept value (ie, } \theta_{i}=0 \text { ) }\end{array}$ & 27.0 & 2.97 & $<.0001$ \\
\hline$\beta_{\mathrm{T}}$ & $\begin{array}{l}\text { Average change in the predicted rating for stimulus } G_{j} v s G_{j-1} \text { for subjects with an average } \Delta P A \text { score (ie, } \\
\Delta P A=0 \text { ) }\end{array}$ & 5.8 & .44 & $<.0001$ \\
\hline$\beta_{\triangle P A}$ & Average change in the predicted rating for stimulus $G_{0}(i e, T=0)$ if $\Delta P A$ increases $1 S D$ & -4.6 & 3.00 & .130 \\
\hline$\beta_{\mathrm{T} \times \triangle P A}$ & Predicted change in the slope of the linear trend if the $\triangle \mathrm{PA}$ score increases $1 \mathrm{SD}$ & .95 & .44 & .032 \\
\hline$\sigma_{\theta}^{2}$ & Variance of the subject-specific predicted ratings for stimulus $G_{0}(i e, T=0)$ & 319.2 & 73.0 & $<.0001$ \\
\hline$\sigma_{\varepsilon}^{2}$ & Variance of the error term & 265.3 & 21.7 & $<.0001$ \\
\hline$R^{\varepsilon}$ & Proportion of explained variance & .681 & & \\
\hline
\end{tabular}

Including a random intercept was necessary in both models, given that 39 and $55 \%$, respectively, were due to differences among participants; $\sigma_{\theta}^{2} /\left(\sigma_{\theta}^{2}+\sigma_{\varepsilon}^{2}\right)$. Furthermore, when omitting the random intercept, the variance explained in the ratings of pain-US expectancy and fear of movement-related pain dropped from 61 to $26 \%$ and from 68 to $20 \%$ for each of the models, respectively.

With respect to the specified regression model, we predicted that the slopes of the pain-US expectancy and fear of movement-related pain ratings across the generalization movements (GSs) would differ for people with relatively high versus low increases in PA, with steeper slopes for individuals with high increases in PA. A steeper slope can be caused by either 1) lower mean fear and expectancy ratings for the $\mathrm{G} 0$ stimulus or 2 ) higher mean fear and expectancy ratings for the $\mathrm{G} 6$ stimulus. Based on previous results associating low PA with deficits in safety learning, we expect that the differences in generalization of US expectancy and fear will be more pronounced for the GSs resembling the original CS- (ie, G0) rather than those resembling the original $\mathrm{CS}+$ (ie, G6). Follow-up contrasts were calculated to test our a priori hypotheses.

\section{Results}

\section{Sample Descriptives and Characteristics of the Pain-US}

Supplementary Table S1 shows the descriptive statistics for characteristics related to the sample and the pain-US.

\section{Manipulation Check: Affect Induction}

Repeated measures analysis of variance indicated a significant interaction between time (pre, post, and FU) and affect induction group (positive vs control), $\mathrm{F}(2,62.8)=6.632, P=.002$, Greenhouse-Geisser corrected. Planned contrasts showed that PA was equally high in both groups before the experimental affect induction (pre: $\mathrm{t}[48]=.703, P=.485$ ), but significantly higher in the positive group than in the control group after the manipulation (post: $\mathrm{t}[41.36]=3.369, P=.002$, sphericity not assumed; see Fig 2). This difference remained significant until after the end of the test of generalization 20 minutes later (FU: $\mathrm{t}[40]=2.053, P=.047$; note: $F U$ measures were available only in a subset of 42 participants). For NA, there was no time by group interaction; $F(1.69$, $67.66)=.559, P=.546$, Greenhouse-Geisser corrected, indicating that the PA manipulation selectively targeted PA but not NA.

\section{Manipulation Check: Acquisition of Pain-US Expectancy and Fear of Movement-Related Pain}

Table 1 presents the results for the multilevel regression model for pain-US expectancy, Table 2 for fear of movement-related pain. There was a significant effect of time on the acquisition of pain-US expectancy and fear of pain-related movement, indicating successful acquisition of expectancy and fear ratings to the CS+ (see Fig 3). The difference in pain-US expectancy between the $\mathrm{CS}-$ and the $\mathrm{CS}+$ at the first rating moment A1 (ie, after 4 conditioning blocks) already reached significance $\left(\mu^{(+)}-\mu^{(-)}=41.96, P<.0001\right)$. At the last rating moment T2 (after the second transfer-of-acquisition block), the difference in US expectancy elicited by the $\mathrm{CS}+$ and the $\mathrm{CS}-$ movements was even larger $\left(\left[\mu^{(+)}+5 \beta_{\top}^{(+)}\right]-\left[\mu^{(-)}+5 \beta_{\top}^{(-)}\right]=131.65, P<.0001\right)$. Moreover, the increase in pain-US expectancy over time was
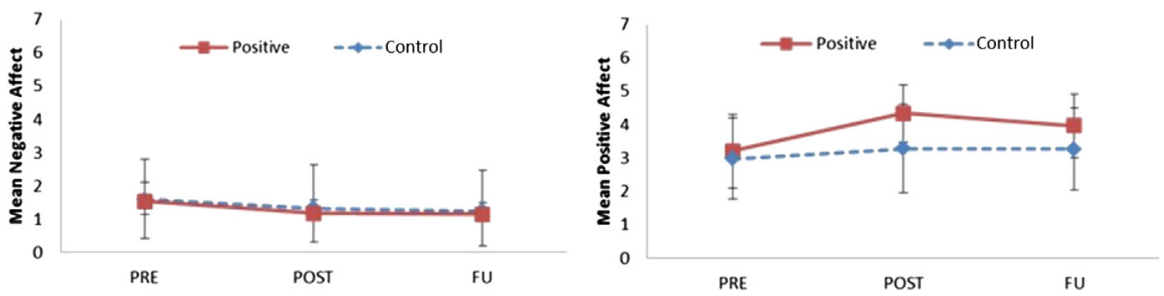

Figure 2. Manipulation check: PA and NA before (pre) and after (post) affect induction in both groups (positive and control), and at FU approximately 20 minutes later, after the test of generalization. 

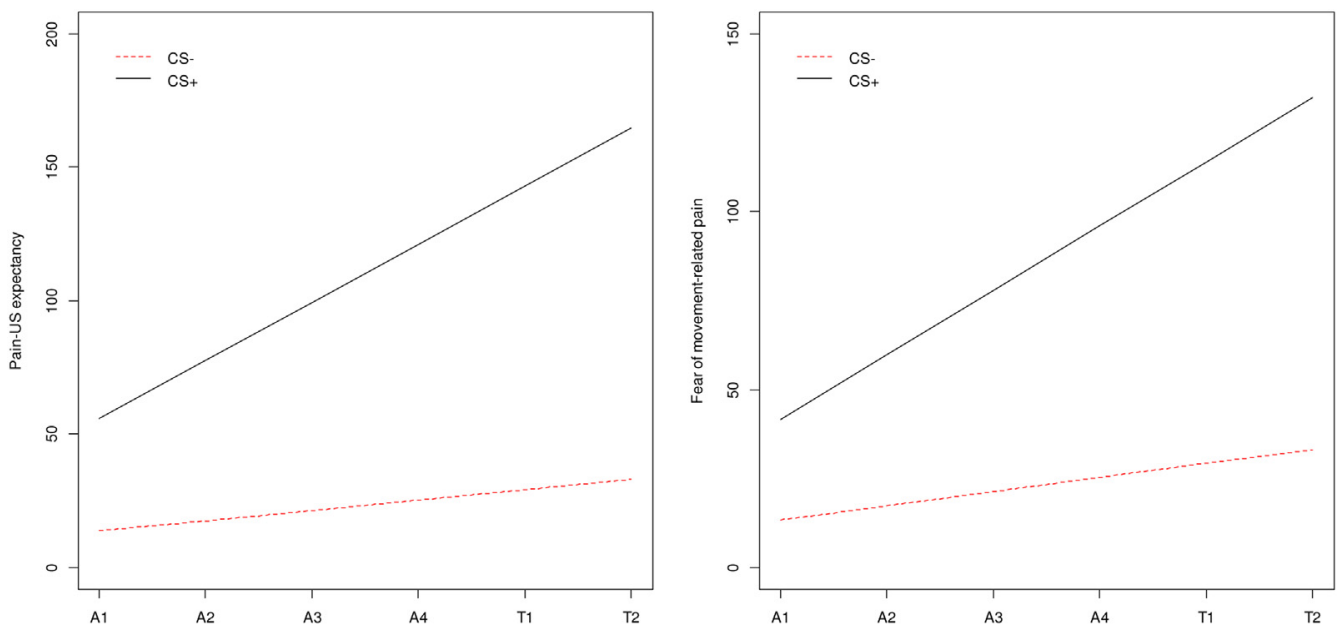

Figure 3. Manipulation check: Relationship between the responses to $C S+$ and $C S-$ movements during the acquisition (A1, $A 2, A 3$, and A4) and transfer (T1 and T2) on measures of pain-US expectancy (left panel) and fear of movement-related pain (right panel).

significantly stronger for the CS+ than for the CS$\left(\beta_{\mathrm{T}}^{(+)}-\beta_{\mathrm{T}}^{(-)}=17.94, P<.0001\right)$. Similarly for the selfreported fear of movement-related pain: the difference between CS- and CS+ at A1 was already significant $\left(\mu^{(+)}-\mu^{(-)}=28.22, P<.0001\right)$; this difference was even larger at the end of the training, at T2 $\left(\left[\mu^{(+)}+5 \beta_{\mathrm{T}}^{(+)}\right]-\left[\mu^{(-)}+5 \beta_{\mathrm{T}}^{(-)}\right]=98.92, P<.0001\right)$, and ratings differentiated further over time (significantly stronger increase for the CS+ than for the CS-, $\left.\beta_{\mathrm{T}}^{(+)}-\beta_{\mathrm{T}}^{(-)}=14.14, P<.0001\right)$. These results indicate that participants learned to expect the occurrence of the US more when performing the $\mathrm{CS}+$ movement than the CS- movement, and that accordingly they were more afraid to perform the $\mathrm{CS}+$ movement than the CS- movement.

\section{Pain-US Expectancy and Fear of Movement-Related Pain During Test of Generalization}

Initial analyses on group differences revealed the expected generalization gradients in both the fear of movement-related pain ratings and the pain-US expectancy ratings (respectively: $\beta_{\mathrm{T}}=5.30, P<.0001$, and $\left.\beta_{\mathrm{T}}=6.54, P<.0001\right)$, but these gradients did not change depending on group status (respectively : $\beta_{\mathrm{T} \times \text { Group }}=1.09, \quad P=.215$, and $\left.\beta_{\mathrm{T} \times \text { Group }}=.66, P=.508\right)$. Although the affect manipulation was successful in the sense that the positive compared to the control manipulation was associated with a significantly greater increase in PA (see Manipulation Check: Emotion Induction), there was a large degree of variation in both groups, as can be seen in Supplementary Table S2. We therefore continued the investigation by examining the effects of the increase in PA from pre to post affect manipulation across the whole sample (responder-analysis). We hypothesized that healthy individuals with relatively high (compared to low) increases in experimentally induced PA would show lower pain-US expectancy and report less fear inhibition in response to the safe CS- movement and to GSs more similar to the original
CS-. Consequently, the slopes of the pain-US expectancy and fear ratings for the stimuli during the test of generalization will differ for people with relatively high versus low increases in PA, with steeper slopes for individuals with high increases in PA. Fig 4 depicts the linear generalization gradients for pain-US expectancy and fear of movement-related pain depending on increase in PA after the experimental manipulation. Please note that the graph is based on a continuous model of increase in PA; the lines reflect calculations based on this model. Supplementary Table S2 is a frequency table providing information about the number of participants actually labeled as scoring relatively low versus relatively high on increases in PA after the experimental affect induction in our sample. Table 3 presents the results for the multilevel regression model for pain-US expectancy, Table 4 for fear of movementrelated pain. First, we observed linear generalization gradients for fear of movement-related pain and pain-US expectancy $\left(\beta_{\mathrm{T}}\right)$ for people with average levels of increase in PA, with stimuli more similar to the original CS + eliciting more pain-US expectancy $\left(\beta_{\mathrm{T}}=6.9\right.$, $P<.0001)$ and fear of movement-related pain $\left(\beta_{\mathrm{T}}=\right.$ 5.8, $P<.0001)$. Given that pain-US expectancy and fear of movement-related pain were measured on a scale of 0 to 100, with SDs of 27.6 and 26.7, respectively, the results can be interpreted as follows: For participants with average $\triangle \mathrm{PA}$, moving 1 stimulus closer toward the CS + was associated with an increase of .25 SD in pain-US expectancy and .22 SD in fear of movement-related pain. Second, for both dependent variables, there was a significant interaction between the generalization gradient (ie, linear trend across GSs) and the increase in PA $\left(\beta_{\mathrm{T} \times \triangle P A}\right)$. For pain-US expectancy, $\beta_{\mathrm{T} \times \triangle P A}=1.01, P=.045$, and for fear of movement-related pain, $\beta_{\mathrm{T} \times \triangle P A}=.95, P=.032$, indicating that the steepness of the slopes increases significantly when the change in PA increases with 1 SD. For participants with low $\triangle P A$, these results mean that moving 1 stimulus closer toward the CS+ was associated with an increase of .18 SD in pain-US expectancy and .15 SD in fear of movement-related pain. For 

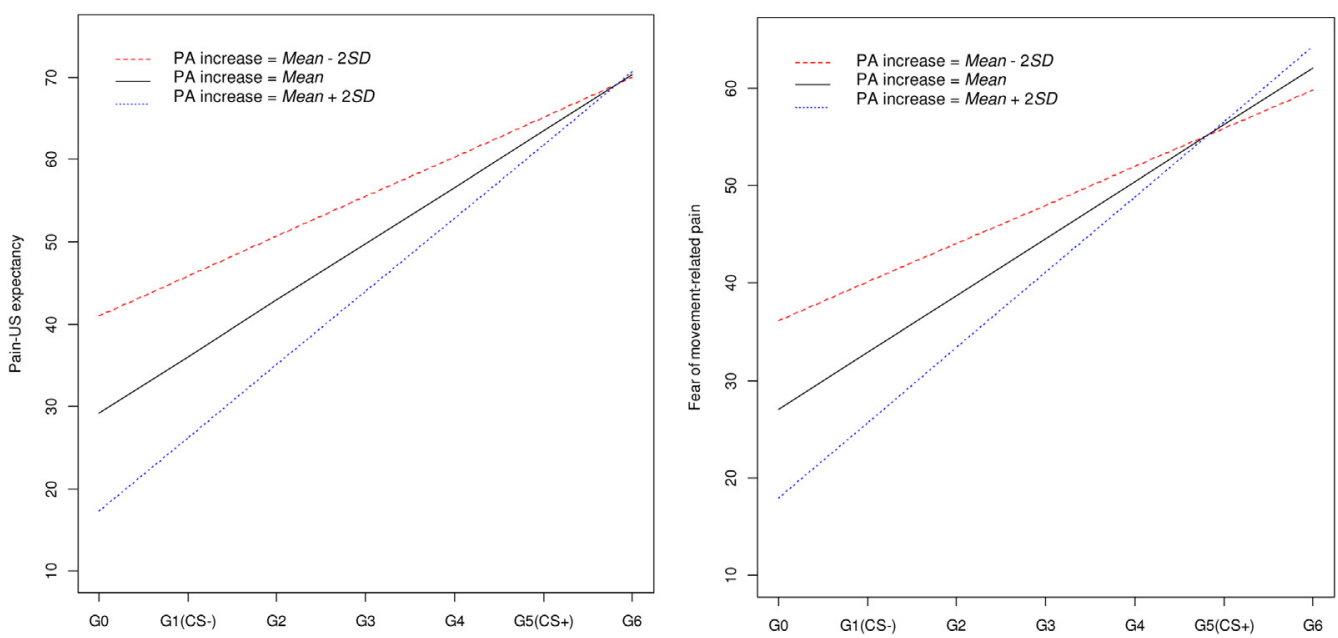

Figure 4. Relationship between GSs for individuals with varying levels of experimentally induced increase in PA on measures of painUS expectancy (left panel) and fear of movement-related pain (right panel). Note that this graph represents calculations based on increase in PA as a continuous variable.

participants with high $\triangle P A$, these increases were significantly steeper, namely, .32 SD for pain-US expectancy and .29 SD for fear of movement-related pain. In line with our hypothesis, the intercept (ie, predicted rating at G0) decreased significantly when PA increased with $1 \mathrm{SD}\left(\beta_{\triangle P A}\right)$ in the pain-US expectancy ratings $\left(\beta_{\triangle P A}=\right.$ $-5.9, P=.036$, which translates into a decrease of .21 $\mathrm{SD})$. For fear of movement-related pain ratings, the decrease was not significant $\left(\beta_{\triangle P A}=-4.6, P=.130\right.$, which translates into a decrease of .17 SD). Planned contrasts were calculated to further inspect the differences in predicted pain-US expectancy and fear of movementrelated pain for participants with high versus low increases of PA (respectively defined as 2 SD above and below average) for the different GSs. As anticipated, there was a significant difference in pain-US expectancy ratings between participants with high versus low increase of PA for the GS that is more extreme than the CS- $\left(G 0 ;-4 \beta_{\triangle P A}=23.6, P=.036\right.$, which translates into a decrease of .86 SD for participants scoring +2 SD compared to -2 SD $\triangle P A$ ) and a borderline significant difference for the original CS$\left(\mathrm{G} 1 ;-4 \beta_{\triangle P A}-4 \beta_{\mathrm{T} \times \triangle P A}=19.6, P=.058\right.$; ie, a decrease of $.71 \mathrm{SD}$ ), but not for any of the other GSs (eg, $\mathrm{G} 6 ;-4 \beta_{\triangle P A}-24 \beta_{\mathrm{T} \times \triangle P A}=-.7, P=.950 ;$ an increase of .03 SD). See Table 5 for an overview of the planned contrasts. For fear of movement-related pain, the pattern of results is very similar in the sense that differences between participants with high versus low increases in PA decrease as stimuli become more similar to the original CS+; however, the difference for the G0 did not reach statistical significance $\left(-4 \beta_{\triangle P A}=18.3, P=.130\right.$; ie, a decrease of .69 SD), nor did it for any other of the GSs.

Finally, in order to evaluate whether the interaction between the generalization gradient and the increase in PA was different for subjects in the positive versus control groups, a random intercept multilevel regression model was conducted that included all main effects, second-order interactions, and a third-order interaction of $\mathrm{T}_{\mathrm{j}}$ (linear trend), $\triangle \mathrm{PA}$, and the (effect-coded) group variable (positive $=1$ vs control $=-1$ ). The results of this analysis indicate that for both dependent variables, the interaction between the generalization gradient and the increase in PA in the PA induction group did not differ from the average interaction effect in both groups $\left(\beta_{\mathrm{T} \times \triangle P A \times \text { Group }}=-.068, P=.91\right.$ for pain-US expectancy, and $\beta_{\mathrm{T} \times \triangle P A \times \text { Group }}=-.55, P=.32$ for fear of movement-related pain).

\section{Discussion}

Fear of pain has long been shown to be a factor underlying the development of chronic disabling pain. ${ }^{11,27}$ Outside the pain field, recent experimental research suggests that excessive generalization of fear of safe stimuli, rather than excessive intensity of fear of danger stimuli, may be particularly

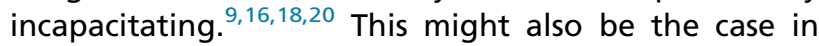
fear of pain. A recent study in our lab indicated that cued pain-related fear spreads selectively to novel movements that were perceptually more similar to the $\mathrm{CS}+$ than to those that were similar to the CS- and thus for the first time showed a generalization gradient for pain-related fear. ${ }^{18}$

On the other hand, studies in patients with chronic pain show that PA in particular may be depleted during episodes of pain and stress, ${ }^{29}$ and that PA inversely predicts pain ratings in subsequent weeks. ${ }^{30}$ An experimental study in healthy participants found that participants with relatively lower trait PA displayed impaired safety learning under extinction compared to participants with relatively higher trait PA, indicating failure of fear inhibition. ${ }^{17}$ PA may thus impact on overgeneralization of fear of pain, yet this area is heavily underinvestigated. A better understanding of how PA influences generalization is important in order to optimize prevention and treatment strategies for patients with disabling chronic pain.

The present study, building on this previous work, aimed to investigate whether induced PA influences generalization of pain-related fear of movement. We 
Table 5. Planned Contrasts for Multilevel Regressions Predicting Pain-US Expectancy and Fear of Movement-Related Pain Ratings During the Generalization Phase for Varying Levels of Increased PA After Either PA Induction or the Control Exercise (ie, Across Groups)

\begin{tabular}{|c|c|c|c|c|}
\hline CoEfficient & Description EFfect for PaIn-US EXPECTANCy & Estimate & $S E$ & P Value \\
\hline$\beta_{\mathrm{T}}-2 \beta_{\mathrm{T} \times \triangle P A}$ & $\begin{array}{l}\text { Average change in predicted rating for stimulus } G_{j} v s G_{j-1} \text { for subjects with a } \\
\Delta P A \text { level of } 2 \text { SDs below average }\end{array}$ & 4.8 & 1.12 & $<.0001$ \\
\hline$\beta_{\mathrm{T}}-\beta_{\mathrm{T} \times \Delta P A}$ & $\begin{array}{l}\text { Average change in predicted rating for stimulus } G_{j} v s G_{j-1} \text { for subjects with a } \\
\Delta P A \text { level of } 1 \text { SD below average }\end{array}$ & 5.9 & .71 & $<.0001$ \\
\hline$\beta_{\mathrm{T}}$ & $\begin{array}{l}\text { Average change in predicted rating for stimulus } G_{j} v s G_{j-1} \text { for subjects with an } \\
\text { average } \Delta \mathrm{PA}\end{array}$ & 6.9 & .50 & $<.0001$ \\
\hline$\beta_{\mathrm{T}}+\beta_{\mathrm{T} \times \Delta P A}$ & $\begin{array}{l}\text { Average change in predicted rating for stimulus } G_{j} v s G_{j-1} \text { for subjects with a } \\
\Delta P A \text { level of } 1 S D \text { above average }\end{array}$ & 7.9 & .71 & $<.0001$ \\
\hline$\beta_{\mathrm{T}}+2 \beta_{\mathrm{T} \times \triangle P A}$ & $\begin{array}{l}\text { Average change in predicted rating for stimulus } G_{j} v s G_{j-1} \text { for subjects with a } \\
\Delta P A \text { level of } 2 \text { SDs above average }\end{array}$ & 8.9 & 1.12 & $<.0001$ \\
\hline$-4 \beta_{\triangle P A}$ & $\begin{array}{l}\text { Difference between average predicted ratings for subjects with low and high } \\
\quad \triangle P A \text { level for } G_{0}(\triangle P A=-2 \text { vs } \triangle P A=2)\end{array}$ & 23.6 & 11.2 & .036 \\
\hline$-4 \beta_{\triangle P A}-4 \beta_{\mathrm{T} \times \triangle P A}$ & $\begin{array}{l}\text { Difference between average predicted ratings for subjects with low and high } \\
\Delta P A \text { level for } G_{1}(\Delta P A=-2 \text { vs } \triangle P A=2)\end{array}$ & 19.6 & 10.3 & .058 \\
\hline$-4 \beta_{\triangle P A}-8 \beta_{\mathrm{T} \times \triangle P A}$ & $\begin{array}{l}\text { Difference between average predicted ratings for subjects with low and high } \\
\Delta P A \text { level for } G_{2}(\Delta P A=-2 \text { vs } \triangle P A=2)\end{array}$ & 15.5 & 9.7 & .110 \\
\hline$-4 \beta_{\triangle P A}-12 \beta_{\mathrm{T} \times \triangle P A}$ & $\begin{array}{l}\text { Difference between average predicted ratings for subjects with low and high } \\
\qquad \Delta \mathrm{PA} \text { level for } \mathrm{G}_{3}(\Delta \mathrm{PA}=-2 \mathrm{vs} \Delta \mathrm{PA}=2)\end{array}$ & 11.5 & 9.5 & .228 \\
\hline$-4 \beta_{\triangle P A}-16 \beta_{\mathrm{T} \times \triangle P A}$ & $\begin{array}{l}\text { Difference between average predicted ratings for subjects with low and high } \\
\Delta \mathrm{PA} \text { level for } \mathrm{G}_{4}(\Delta \mathrm{PA}=-2 \mathrm{vs} \Delta \mathrm{PA}=2)\end{array}$ & 7.4 & 9.7 & .446 \\
\hline$-4 \beta_{\triangle P A}-20 \beta_{\mathrm{T} \times \Delta P A}$ & $\begin{array}{l}\text { Difference between average predicted ratings for subjects with low and high } \\
\Delta P A \text { level for } G_{5}(\Delta P A=-2 \text { vs } \triangle P A=2)\end{array}$ & 3.3 & 10.3 & .746 \\
\hline$-4 \beta_{\triangle P A}-24 \beta_{\mathrm{T} \times \triangle P A}$ & $\begin{array}{l}\text { Difference between average predicted ratings for subjects with low and high } \\
\quad \Delta \mathrm{PA} \text { level for } \mathrm{G}_{6}(\triangle \mathrm{PA}=-2 \mathrm{vs} \triangle \mathrm{PA}=2)\end{array}$ & -.7 & 11.2 & .950 \\
\hline Coefficient & Description Effect for Fear of Movement-Related Pain & ESTIMATE & $S E$ & P Value \\
\hline$\beta_{\mathrm{T}}-2 \beta_{\mathrm{T} \times \triangle P A}$ & $\begin{array}{l}\text { Average change in predicted rating for stimulus } G_{j} v s G_{j-1} \text { for subjects with a } \\
\Delta P A \text { level of } 2 \text { SDs below average }\end{array}$ & 3.9 & .98 & $<.0001$ \\
\hline$\beta_{\mathrm{T}}-\beta_{\mathrm{T} \times \Delta P A}$ & $\begin{array}{l}\text { Average change in predicted rating for stimulus } G_{j} v s G_{j-1} \text { for subjects with a } \\
\Delta \text { PA level of } 1 \text { SD below average }\end{array}$ & 4.9 & .62 & $<.0001$ \\
\hline$\beta_{\top}$ & $\begin{array}{l}\text { Average change in predicted rating for stimulus } G_{j} v s G_{j-1} \text { for subjects with } \\
\text { an average } \triangle P A\end{array}$ & 5.8 & .44 & $<.0001$ \\
\hline$\beta_{\mathrm{T}}+\beta_{\mathrm{T} \times \triangle P A}$ & $\begin{array}{l}\text { Average change in predicted rating for stimulus } G_{j} v s G_{j-1} \text { for subjects with a } \\
\Delta \text { PA level of } 1 S D \text { above average }\end{array}$ & 6.8 & .62 & $<.0001$ \\
\hline$\beta_{\mathrm{T}}+2 \beta_{\mathrm{T} \times \triangle P A}$ & $\begin{array}{l}\text { Average change in predicted rating for stimulus } G_{j} v s G_{j-1} \text { for subjects with a } \\
\Delta \text { PA level of } 2 \text { SDs above average }\end{array}$ & 7.7 & .98 & $<.0001$ \\
\hline$-4 \beta_{\triangle P A}$ & $\begin{array}{l}\text { Difference between average predicted ratings for subjects with low and high } \\
\Delta \mathrm{PA} \text { level for } \mathrm{G}_{0}(\Delta \mathrm{PA}=-2 \mathrm{vs} \triangle \mathrm{PA}=2)\end{array}$ & 18.3 & 12.0 & .130 \\
\hline$-4 \beta_{\triangle P A}-4 \beta_{\mathrm{T} \times \triangle P A}$ & $\begin{array}{l}\text { Difference between average predicted ratings for subjects with low and high } \\
\Delta P A \text { level for } G_{1}(\triangle P A=-2 \text { vs } \triangle P A=2)\end{array}$ & 14.5 & 11.4 & .204 \\
\hline$-4 \beta_{\triangle P A}-8 \beta_{\mathrm{T} \times \triangle P A}$ & $\begin{array}{l}\text { Difference between average predicted for subjects with low and high } \\
\Delta P A \text { level for } G_{2}(\triangle P A=-2 \text { vs } \triangle P A=2)\end{array}$ & 10.7 & 10.9 & .330 \\
\hline$-4 \beta_{\triangle P A}-12 \beta_{T \times \triangle P A}$ & $\begin{array}{l}\text { Difference between average predicted ratings for subjects with low and high } \\
\Delta \mathrm{PA} \text { level for } \mathrm{G}_{3}(\triangle \mathrm{PA}=-2 \text { vs } \triangle \mathrm{PA}=2)\end{array}$ & 6.9 & 10.8 & .524 \\
\hline$-4 \beta_{\triangle P A}-16 \beta_{\mathrm{T} \times \Delta P A}$ & $\begin{array}{l}\text { Difference between average predicted ratings for subjects with low and high } \\
\Delta \mathrm{PA} \text { level for } \mathrm{G}_{4}(\Delta \mathrm{PA}=-2 \text { vs } \triangle \mathrm{PA}=2)\end{array}$ & 3.1 & 10.9 & .777 \\
\hline$-4 \beta_{\triangle P A}-20 \beta_{T \times \Delta P A}$ & $\begin{array}{l}\text { Difference between average predicted ratings for subjects with low and high } \\
\Delta \mathrm{PA} \text { level for } \mathrm{G}_{5}(\Delta \mathrm{PA}=-2 \text { vs } \triangle \mathrm{PA}=2)\end{array}$ & -.7 & 11.4 & .952 \\
\hline$-4 \beta_{\triangle P A}-24 \beta_{\mathrm{T} \times \Delta P A}$ & $\begin{array}{l}\text { Difference between average predicted ratings for subjects with low and high } \\
\Delta P A \text { level for } G_{6}(\Delta P A=-2 \text { vs } \triangle P A=2)\end{array}$ & -4.5 & 12.0 & .710 \\
\hline
\end{tabular}

hypothesized that induced PA would limit the spreading of acquired pain-US expectancy and fear related to a specific movement $(\mathrm{CS}+)$ to novel yet similar movements (GSs). Given prior evidence linking PA to safety learning, ${ }^{17}$ we hypothesized that differences would be most pronounced on stimuli that are more related to the CS- but nonsignificant for stimuli that are more similar to the original $\mathrm{CS}+$. For high levels of induced PA, lower fear and pain-US expectancy ratings in response to stimuli in the CS- region should thus result in a steeper slope (because of similar ratings in response to stimuli surrounding the $\mathrm{CS}+$ ) characterized by a lower intercept (responses to generalization movement closer to (S-), compared to lower 
levels of induced PA. To test these hypotheses, we randomly assigned participants to either the BPS exercise (to induce PA) or a control exercise after they had experienced that one movement $(\mathrm{CS}+)$ but not another (CS-) was consistently paired with a painful electrocutaneous stimulus (pain-US). After the affect induction phase, participants were asked to perform the original movements as well as 5 novel movements with varying degrees of similarity with the CS- and the $\mathrm{CS}+$

First, we replicated recent work demonstrating generalization gradients in cued pain-related fear in a psychophysiological fear measure, now in both the verbal ratings of fear and pain-US expectancy. ${ }^{18}$ Pain-US expectancy and fear were stronger for GSs that were more similar to the CS+ compared to GSs that were more similar to the CS-. Second, although there was no overall effect of affect-induction group (PA induction group or control group), we found that individual increases in PA were related to generalization of painUS expectancy and fear of movement-related pain, as hypothesized. Participants with a higher increase in PA displayed generalization gradients with significantly lower intercepts and steeper slopes. In other words, they displayed lower pain-US expectancy and fear of stimuli similar to the CS- but not of stimuli similar to the CS+, compared to participants with a smaller or no increase in PA. The absence of a group effect may be related to the variability in responding to the experimental affect manipulations. For example, although the BPS exercise was significantly more successful in increasing PA compared to the Typical Day control exercise, $52 \%$ of individuals in the control group also reacted with a mild increase in PA, thus adding noise to the experimental manipulation. In a previous study, post hoc "responder" analyses using the actual increase in optimism (by analogy with $\triangle \mathrm{PA}$ ) after the BPS as a predictor also proved to have more statistical power than just analyzing the differences between the experimental groups (ML.P., 2014, unpublished data). Combined with the fact that the experimental situation was rather strong ${ }^{14}$ in the sense that a significant level of fear and pain was produced by the experimental pain-related fear conditioning procedure, this could have prevented the emergence of a group effect. It is not unreasonable to argue that interrupting the fear conditioning procedure might have increased PA in the control group as well, or that describing a typical day can be positive for some people, especially in a sample of emotionally and physically healthy university students.

These findings may have important implications for the prevention and treatment of fear of movementrelated pain in chronic pain patients. For the prevention of chronic pain, the main implication is that patients with acute pain complaints may benefit from exercises targeting PA in an early stage. Increased PA may then limit the spreading of fear of pain to dangerous movements directly associated with pain, while inhibiting the spreading of fear inhibition in response to more unrelated, realistically safe movements. With regard to treat- ment, the most important implication is that increasing positive mood at the start of treatment or before homework exercises may render exposure sessions more effective by promoting safety learning. Furthermore, the BPS exercise enhancing PA and optimism has also been shown to reduce sensitivity for experimental pain stimuli and reduce cognitive interference caused by pain. ${ }^{2,6}$ Taken together, these findings suggest that increasing PA might be beneficial in the initial stages as well as later on during treatment. However, more research is clearly needed in this area, regarding both experimental research on underlying mechanisms as well as research in patients with acute or chronic pain complaints.

Methodologic strengths of the current study include the following:

1. We used a partial reinforcement scheme, in which the $\mathrm{CS}+$ was reinforced also during its first presentation in the test of generalization.

2. The CS + arm-movement itself, rather than only the completion of the movement, was paired with a pain-US (painful electrocutaneous stimulation), thereby more accurately mimicking real-life movement-related pain, compared to previous experimental studies.

3. Movement direction was signaled through consistent color coding that was independent of stimulus type and US occurrence. This means that, in comparison with Meulders et al, $^{18}$ who used numbers to identify movement directions, additional visual CSs were eliminated.

4. Participants were not exposed to the GSs beforehand; participants had experience with the CS+ and the CS- movement but not with the GSs during the test of generalization. This is important because prior experience can enhance discrimination learning, ${ }^{3}$ possibly resulting in an increased focus on differences between the CSs and GSs, improved categorization, and thus less generalization.

Limitations of the present study include the suboptimal measurement of the startle eyeblink response and in particular the timing of the acoustic startle probe, which was confounded by the pain-US administration and therefore could not be used as an index of anticipatory fear of movement-related pain. Therefore, these results were omitted in this article. Future research may provide a tonic pain stimulus that increases in intensity toward the end of the CS + movements, thereby rendering startle measures possible again as well as resembling the experience of chronic pain patients even more closely, given that they are rarely truly pain-free. Another limitation concerns the choice of the control intervention, because writing about and visualizing one's typical day seems to have induced PA in some participants and may induce NA in others, which probably limited the power to observe between-group differences given the sample size. Future studies should therefore strive to find a more consistently neutral control intervention.

To conclude, our study demonstrated for the first time that experimentally induced PA promotes safety learning by inhibiting fear and pain-US expectancy 
Geschwind et al

to stimuli proprioceptively more similar to the original CS-, thereby inhibiting generalization of fear learning. This may have important implications for the prevention and treatment of clinical pain disorders.

\section{References}

1. Asmundson GJ, Norton PJ, Veloso F: Anxiety sensitivity and fear of pain in patients with recurring headaches. Behav Res Ther 37:703-713, 1999

2. Boselie JJ, Vancleef LM, Smeets T, Peters ML: Increasing optimism abolishes pain-induced impairments in executive task performance. Pain 155:334-340, 2014

3. Flor H, Denke C, Schaefer M, Grusser S: Effect of sensory discrimination training on cortical reorganisation and phantom limb pain. Lancet 357:1763-1764, 2001

4. Fredrickson BL: The value of positive emotions: The emerging science of positive psychology is coming to understand why it's good to feel good. Am Sci 91:330-335, 2003

5. Fredrickson BL, Mancuso RA, Branigan C, Tugade MM: The undoing effect of positive emotions. Motiv Emot 24: 237-258, 2000

6. Hanssen MM, Peters ML, Vlaeyen JWS, Meevissen YMC, Vancleef LMG: Optimism lowers pain: Evidence of the causal status and underlying mechanisms. Pain 154:53-58, 2013

7. SAS Institute Inc: SAS/STAT® 9.3 User's Guide. Cary, NC, SAS Institute Inc, 2011

8. Izard CE, Dougherty FE, Bloxom BM, Kotsch NE: The Differential Emotions Scale: A Method of Measuring the Subjective Meaning of Experience of Discrete Emotions. Nashville, TN, Vanderbilt University, Department of Psychology, 1974

9. Jovanovic T, Kazama A, Bachevalier J, Davis M: Impaired safety signal learning may be a biomarker of PTSD. Neuropharmacology 62:695-704, 2012

10. Kleinstäuber $M$, Jasper $K$, Schweda I, Hiller W, Andersson G, Weise C: The role of fear-avoidance cognitions and behaviors in patients with chronic tinnitus. Cogn Behav Ther 42:84-99, 2013

11. Leeuw M, Goossens ME, Linton SJ, Crombez G, Boersma K, Vlaeyen JW: The fear-avoidance model of musculoskeletal pain: Current state of scientific evidence. J Behav Med 30:77-94, 2007

12. Leeuw M, Goossens ME, van Breukelen GJ, Boersma K, Vlaeyen JW: Measuring perceived harmfulness of physical activities in patients with chronic low back pain: The photograph series of daily activities-short electronic version. J Pain 8:840-849, 2007

13. Lissek S, Grillon C: Overgeneralization of conditioned fear in the anxiety disorders. J Psychol 218:146-148, 2010

14. Lissek S, Pine DS, Grillon C: The strong situation: A potential impediment to studying the psychobiology and pharmacology of anxiety disorders. Biol Psychol 72: 265-270, 2006

15. Lissek S, Rabin S, Heller RE, Lukenbaugh D, Geraci M, Pine DS, Grillon C: Overgeneralization of conditioned fear as a pathogenic marker of panic disorder. Am J Psychiatry $167: 47-55,2010$

\section{Supplementary Data}

Supplementary data related to this article can be found at http://dx.doi.org/10.1016/j.jpain.2014.12.003.

16. Lissek S, Rabin SJ, McDowell DJ, Dvir S, Bradford DE, Geraci M, Pine DS, Grillon C: Impaired discriminative fearconditioning resulting from elevated fear responding to learned safety cues among individuals with panic disorder. Behav Res Ther 47:111-118, 2009

17. Meulders A, Meulders M, Vlaeyen JWS: Positive affect protects against deficient safety learning during extinction of fear of movement-related pain in healthy individuals scoring relatively high on trait anxiety. J Pain 15:632-644, 2014

18. Meulders A, Vandebroek N, Vervliet B, Vlaeyen JWS: Generalization gradients in cued and contextual pain related fear: An experimental study in healthy participants. Front Hum Neurosci 7:345, 2013

19. Meulders A, Vansteenwegen D, Vlaeyen JWS: The acquisition of fear of movement-related pain and associative learning: A novel pain-relevant human fear conditioning paradigm. Pain 152:2460-2469, 2011

20. Meulders A, Vlaeyen JWS: The acquisition and generalization of cued and contextual pain-related fear: An experimental study using a voluntary movement paradigm. Pain $154: 272-282,2013$

21. Mitchell RLC, Phillips LH: The psychological, neurochemical and functional neuroanatomical mediators of the effects of positive and negative mood on executive functions. Neuropsychologia 45:617, 2007

22. Peters ML, Flink IK, Boersma K, Linton SJ: Manipulating optimism: Can imagining a best possible self be used to increase positive future expectancies? J Positive Psychol 5: 204-211, 2010

23. Schaefer A, Nils F, Sanchez X, Philippot P: Assessing the effectiveness of a large database of emotion-eliciting films: A new tool for emotion researchers. Cogn Emot 24: $1153-1172,2010$

24. Spruyt A, Clarysse J, Vansteenwegen D, Baeyens $F_{1}$ Hermans D: Affect 4.0: A free software package for implementing psychological and psychophysiological experiments. Exp Psychol 57:36, 2010

25. Sturgeon JA, Zautra AJ: Psychological resilience, pain catastrophizing, and positive emotions: Perspectives on comprehensive modeling of individual pain adaptation. Curr Pain Headache Rep 17:317, 2013

26. Verbeke G, Molenberghs G: Linear Mixed Models for Longitudinal Data. New York, Springer, 2000

27. Vlaeyen JW, Linton SJ: Fear-avoidance and its consequences in chronic musculoskeletal pain: A state of the art. Pain 85:317-332, 2000

28. Vlaeyen JW, Linton SJ: Fear-avoidance model of chronic musculoskeletal pain: 12 years on. Pain 153:1144-1147, 2012

29. Zautra AJ, Fasman R, Reich JW, Harakas P, Johnson LM, Olmsted ME, Davis MC: Fibromyalgia: Evidence for deficits in positive affect regulation. Psychosom Med 67:147-155, 2005

30. Zautra AJ, Johnson LM, Davis MC: Positive affect as a source of resilience for women in chronic pain. J Consult Clin Psychol 73:212-220, 2005 